\title{
La experiencia narrada como vehículo de construcción colectiva en la música de Luc Ferrari ${ }^{*}$
}

\author{
Alejandro Reyna \\ [Universidad Nacional del Litoral]
}

\begin{abstract}
Resumen El artículo propone interpretar la experiencia narrada que aparece en la música de Ferrari como una búsqueda por articular un sentido colectivo. En otras palabras, toda la exposición de la vida personal del compositor que aparece en las obras posee un sentido que excede la simple anécdota personal. Luego de plantear una definición de experiencia considerada pertinente en relación a nuestros objetivos, en un primer momento se habla de la obra Hétérozygote y del field recording como "gati\|lo" de experiencias. A continuación, nos abocamos a reflexionar sobre las historias compartidas por Ferrari. Finalmente, en el apartado «Lo colectivo en el gesto de contarse", se analiza en términos colectivos la exposición personal que propone Ferrari, tomando como ejemplo la obra Chantal, ou le portrait d'une villageoise.
\end{abstract}

Summary The article proposes to interpret the narrated experience that appears in Ferrari's music as a search to articulate a collective meaning. In other words, the entire exposition of the composer's personal life that appears in the works has a meaning that goes beyond a simple personal anecdote. After proposing a definition of experience considered relevant in relation to our objectives, at first the work Hétérozygote and field recording are spoken of as a trigger of experiences. Next, we set out to reflect on the stories shared by Ferrari. Finally, in the section "The collective in the gesture of counting oneself", the personal exhibition proposed by Ferrari is analyzed in collective terms, taking as an example the work Chantal, ou le portrait d'une villageoise.

\footnotetext{
* El presente artículo fue presentado, en una versión abreviada, dentro del Coloquio de la Asociación Argentina de Musicología en 2019, realizado en el marco de "Músicos en Congreso - VII edición", en la ciudad de Santa Fe. La misma contó con la interpelación de Gonzalo Bifarella, a quien se agradece por las sugerencias, que fueron incorporadas en el presente artículo. Por otra parte, las reflexiones que aparecen a continuación se encuentran en mi tesis doctoral, pero en dicho marco aparecen en forma ampliada. Teniendo en cuenta la extensión prevista en la presente publicación y la prolífica composición de Ferrari, las proposiciones que aparecen a continuación se desarrollan de forma sucinta. Para una versión más detallada, ver Reyna, 2016.
} 
La música organiza la memoria

$\sim$ Herrero, 2019

Donde la experiencia domina en sentido estricto, somos testigos de la conjunción, dentro de la memoria, entre contenidos del pasado individual y contenidos del pasado colectivo $\sim$ Benjamin, 1974: I55

Luc Ferrari es un compositor francés, perteneciente a la primera camada de compositores asociados al GRM (Grupo de investigación musical) dirigido por Pierre Schaeffer ${ }^{1}$. A diferencia de la voluntad de abstracción reivindicada por la música concreta ${ }^{2}$, la composición de Ferrari se caracteriza, a partir de mediados de los '6o, por la aparición progresiva de grabaciones de momentos provenientes de su vida cotidiana. Componiendo a partir de dichas grabaciones, Ferrari explota en términos estéticos el mundo que lo rodea, yendo incluso hasta recurrir a su vida personal ${ }^{3}$. El presente artículo se propone pensar dicho gesto en términos estéticos y éticos. Escuchar a alguien contar su vida puede contener un sentido que concierne a todos como sociedad. Se trazan puentes con uno mismo y con los otros, por lo que podríamos llamarlo político en el sentido de que concierne a la polis. Lo que puede parecer entonces, en primer lugar, narcisismo, megalomanía o exhibicionismo busca en realidad poner en música el valor social que inicia lo vivido al momento de su transmisión a través de historias. Se trata de movilizar el sentido colectivo de la experiencia. El objetivo del artículo es intentar entender la forma en la que esto se produce en la música de Ferrari.

Para realizar dicho objetivo, el escrito se estructura en tres partes, introducidas por un breve desarrollo conceptual. Así, luego de plantear una definición de experiencia considerada pertinente en relación a nuestros objetivos, en un primer momento se hablará de la obra Hétérozygote y del field recording

1 Para más información acerca del GRM, su historia y su relación con Ferrari ver: Caux, 2002.

2 Sobre la voluntad primera de Schaeffer respecto a la abstracción de las fuentes sonoras y la música concreta es difícil ser terminantes. A la lectura de $A$ la recherche d'une musique concrète, que se presenta como una parte de los diarios de investigación del autor en la época, vemos un posicionamiento no tan categórico respecto al tema. Sin embargo, en publicaciones posteriores, la voluntad de Schaeffer de abstraer los sonidos de sus fuentes es terminante. Michel Chion aborda la cuestión en La musique concrète, art des sons fixés (2009).

3 Ver, en ese sentido, «Experiencia y cristalización» página 7. 
como "gatillo» de experiencias. Para desarrollar dicha noción nos apoyaremos en ideas de la musicóloga inglesa Katharine Norman. Luego, en el apartado «Experiencia y cristalización», nos abocaremos a reflexionar sobre las historias compartidas por Ferrari. Las mismas serán interpretadas como una búsqueda de reforzar la dimensión común que pueden tener las experiencias. Finalmente, en el apartado "Lo colectivo en el gesto de contarse», se analizará en términos colectivos la exposición personal que propone Ferrari, tomando como ejemplo la obra Chantal, ou le portrait d'une villageoise. Se intentará pensar acerca de los valores aludidos por el compositor, tomando conceptos del pensamiento de Leonor Arfuch.

Como se ha dicho anteriormente, antes de abordar nuestros objetivos, consideramos pertinente introducir la reflexión con algunas definiciones respecto del concepto de experiencia. Proponer el concepto de experiencia en el marco de un trabajo musicológico no es un ejercicio que esté exento de riesgos, considerando la larga y compleja historia que posee en filosofía ${ }^{4}$. La mera mención de dicho concepto acarrea entonces un bagaje conceptual con un recorrido importante y diverso, lo que no facilita nuestra tarea. En pos de centrarnos en nuestros objetivos y no derivar en un campo que rápidamente puede volverse inabordable, a continuación vamos a citar algunas definiciones, como para poder entender globalmente el uso del término y particularmente la dimensión del mismo que puede resultarnos útil.

Jean-Marie Schaeffer, en su libro la experiencia estética, dedica una parte de su primer capítulo a la definición de experiencia. Basándose parcialmente en una publicación de David Carr ${ }^{5}$, Jean-Marie Schaeffer se ocupa de detallar distintas acepciones a las que refiere el concepto. Hacia el final de dicha exposición, en un glosario que clarifica los conceptos utilizados, podemos leer:

En francés [como en español] existe sólo un término para referirnos, por un lado, a la experiencia como proceso y cristalización de nuestras interacciones con el mundo (por ejemplo, «este libro contiene la experiencia de toda una vida») y experiencia como una vivencia fenoménica subjetiva (por ejemplo, «la experiencia de plenitud que sentí en ese momento fue extraordina-

4 Por mencionar algunos ejemplos, quedándonos únicamente en la historia del pensamiento occidental: Aristóteles, el empirismo de Hume o Locke, Kant, Hegel, sin olvidar el movimiento de la fenomenología, entre otros.

5 En uno de los capítulos del libro, Carr se ocupa de trazar una historia del término en filosofía. Ver Carr, 2014. 
ria»), mientras que el alemán distingue lexicalmente entre Erfahrungy Erlebnis (Schaeffer, 2015: 322). ${ }^{6}$

La definición de Jean-Marie Schaeffer puede resultarnos útil porque pone en relieve dos aspectos que existen dentro del concepto de experiencia, sobre los cuales las distintas definiciones se inclinan en mayor o en menor medida. Si bien estas dos acepciones del concepto en español se condensan en el término experiencia, en alemán (el idioma en el que escriben una buena parte de los filósofos de renombre que trabajan el tema) cada una de ellas ofrece un término diferente. Erlebnis implica la primera acepción a la que nos referimos, es decir, experiencia en el sentido de interacción (principalmente sensitiva). Erfahrung, por otro lado, implica el segundo aspecto, es decir, experiencia en el sentido de acumulación de dichas interacciones. En todo caso, a nuestros fines, propongo que retengamos estas dos dimensiones del término, ya que más adelante van a sernos de utilidad.

\section{EL «FIELD RECORDING» COMO GATILLO DE EXPERIENCIAS}

Para desarrollar esta primer idea, se tomará como ejemplo un extracto de una obra de 1964: Hétérozygote. Se trata de una pieza que marcará la carrera de Ferrari, tanto a nivel compositivo como «logístico», de alguna manera. En ese sentido, la obra tiene una historia particular respecto a su presentación, que terminó por desencadenar la partida de Ferrari del GRM y, consecuentemente, el alejamiento de sus estudios de grabación ${ }^{7}$ - de ahí «logístico», ya que a partir de ese momento emprenderá su trabajo de composición desde estudios personales -. Por cuestiones en parte estéticas, marcará también un distanciamiento con Pierre Schaeffer y con el movimiento de la música concreta.

A partir de Hétérozygote, la música de Ferrari abrirá la puerta a lo que el compositor llamó sonidos anecdóticos, es decir, sonidos provenientes del común de los días, insignificantes a priori. Así, una parte de los sonidos grabados que presenta Hétérozygote aparecerá «como tal», sin enmascaramientos o tratamien-

\footnotetext{
6 La traducción es nuestra. Original: En français il n'existe qu'un seul terme pour désigner à la fois l'expérience comme processus et cristallisation de nos interactions avec le monde (par exemple "ce libre contient l'expérience de toute une vie") et l'expérience comme vécu phénoménal subjectif (par exemple "l'expérience de plénitude que j'ai ressentie à ce moment-là fut extraordinaire"), alors que l'allemand distingue lexicalement entre la Erfahrung et Erlebnis. 7 Para más información al respecto, ver las entrevistas a Ferrari de Jacqueline Caux (2002).
} 
tos electroacústicos que oculten su fuente sonora original: el mundo sonoro cotidiano que nos rodea. Si la música concreta proponía ocultar las fuentes sonoras, para que los auditores escuchen los sonidos en sí (la llamada «escucha reducida $\left.{ }^{8}\right)$, en Hétérozygote sus orígenes son asumidos, de alguna manera. En la obra, reconocemos conversaciones, aviones, animales, en definitiva: sonidos captados en el exterior sin tratamientos que nos impidan percibir su origen, atrapados al azar del mundo de todos los días. Propongo centrarnos en algunos instantes de la obra, entre 4'42" y s'43".

Partiendo de lo que Denis Smalley llama el source-bonding (1994) o Michel Chion El cordón causal (1999), la escucha tiende a querer reconocer las fuentes sonoras y figurar la situación donde pudo haberse producido el sonido. Los sonidos del ejemplo nos inducen a figurar el contexto original, a proyectar la situación que no vemos. Escuchamos entonces en una ola de mar, clara, algunos instantes de viento y la frase que dice: «Ah non! Tu penses qu'à manger» que podríamos traducir por «Oh, no! Vos pensás solamente en comer». Estos sonidos aparecen en medio de una obra que hasta ese momento podía entrar en la clasificación de música concreta, siguiendo los parámetros de Schaeffer. Pero con esta aparición, no se trata solamente de sonidos reconocibles: la ola, el chiste, conforman un momento de playa. Un lugar posiblemente asociado a las vacaciones, al verano, al mar, al descanso... Ferrari explota el potencial representativo de la tecnología, trabaja con la presencia de lo real que permite el magnetófono, para mostrar un momento común en la vida de mucha gente. Vemos en su gesto una cierta provocación, una reivindicación de lo que nos es próximo, cercano.

Diversas propuestas musicológicas y artísticas nombran de forma diferente a manifestaciones sonoras que se asemejan al momento de playa, en Hétérozygote. Fonografía es una acepción utilizada por Pierre-Yves Macé (2009) y FrançoisBernard Mâche (1998). Una fuerza del término es que proyecta una cierta idea de «objetividad» o neutralidad en la captura mecánica del sonido, debido a su similitud respecto al término fotografía; pero por otro lado el término posee la desventaja de poder ser ampliamente entendido en tanto grabación sonora. Por su parte, Katharine Norman parece privilegiar el término real-world-sounds (1996). Una parte importante de las investigaciones se inclinan por el término field recording 9 . En todos los casos, se trata de categorías que definen prácticas

8 Podemos observar un ejemplo revelador en ese sentido en el gesto de Schaeffer de cambiar el ataque de un sonido de oboe para que se "vvelva otra cosa" (Schaeffer, 1952). Acerca de escucha reducida, ver Schaeffer, 1966.

9 Es preciso notar aquí que el término field recording abarca prácticas diversas, como la bioacústica. No se limita al campo de la creación artística. En lo que refiere a su uso en composiciones artísticas, ver, por ejemplo: Benson y 
que emergen luego de la comercialización de los magnetófonos a principios de los ‘ 60 , consistiendo principalmente en la utilización de capturas sonoras hechas fuera del estudio de grabación en obras musicales. Dichas tecnologías, en ese sentido, fueron permitiendo que los compositores puedan expresarse estableciendo un diálogo particular entre entorno personal y obra.

Aquí llegamos a una primera idea: el tipo de field recordings que utiliza Ferrari, de momentos de vida como los que aparecen en Hétérozygote, pone en juego cuestiones que tienen que ver con la experiencia común, con una dimensión compartida de las vivencias personales. La presencia de estos «sonidos del mundo» en las obras hace resonar nuestras experiencias. Se trata de una idea que encontramos, entre otros ${ }^{10}$, en el pensamiento de la musicóloga inglesa Katharine Norman, quien trabaja en análisis de músicas electroacústicas. Podemos leer dicha idea en su artículo «Telling tales»:

La música en la que los sonidos del mundo real proporcionan material y el sujeto puede mirar hacia atrás en la realidad; revela una preocupación compositiva por explorar tanto los timbres de la experiencia recolectada como el timbre de los sonidos grabados. ${ }^{11}$ (Norman, 1994: I03)

La cita de Katharine Norman es un antecedente importante respecto a la utilización del concepto de experiencia en el análisis de músicas que utilizan field recordings (realworld sounds, en sus palabras). La musicóloga plantea en el texto un punto central para la temática que nos convoca: la aparición de «sonidos reales» dentro de obras musicales puede mirar retrospectivamente en nuestras realidades, revelando cuestiones que exploran tanto el timbre de los sonidos grabados como de nuestras experiencias. Partiendo del uso de los field recordings como materiales, que estructuran la forma musical, y como sujetos, el oyente reconoce algo en estos momentos-música: la ola, para tomar un ejemplo personal, me lleva a la costa y mis vacaciones de infancia. Nuestra experiencia resuena con la anécdota de Ferrari, lo que nos lleva a verter nuestras vivencias subjetivas en el momento de la escucha. Es la razón de la metáfora del «gatillo» utilizada en el subtítulo: los field recordings de las obras disparan estos con-

Montgomery, 2018 o Cobussen, Meelberg y Truax, 2016.

10 Podemos citar, para dar una referencia de mayor actualidad, el conjunto de artículos que se ocupan de la sección "Listening and memory" en Cobussen, Meelberg y Truax, 2016.

11 La traducción es nuestra. Original: Music in which real-world sounds provide both material and subject can purposefully look back in reality; it reveals a compositional concern to explore the timbres of recollected experience as much as the timbre of recorded sounds. 
glomerados de experiencias. En la edición de la Hétérozygote en vinilo de 1969, podemos leer:

Un día me fui, por razones que no voy a explicar, con una grabadora que no era mía. He viajado, no muy lejos, pero mucho y he grabado cosas de la vida. Así nació Hétérozygote, primer obra de un género que llamé música anecdótica. [...] El uso de elementos realistas me permitió contar una historia, o permite al oyente inventar imágenes, porque el montaje ofrece ambigüedades [...]. Lo que me interesa es que Hétérozygote me sea contado por otras personas, que sea reescrita con sus historias y que, por lo tanto, el disco no sea un objeto abstracto, sino un intercambio vivo. ${ }^{12}$ (Ferrari, 1969)

En estas declaraciones de la década de 1960 podemos vislumbrar los inicios de una búsqueda que se llevará a cabo a lo largo de la carrera del compositor. Encontramos allí la voluntad de grabar "cosas de la vida», de contar historias de una manera ambigua, lo que permite al oyente proyectar sus propias imágenes. También percibimos el deseo de que otros «reescriban» la obra a partir de sus vivencias, haciendo del disco un intercambio y no sólo un objeto abstracto. El compositor considera los mundos internos de los oyentes, son parte de su reflexión artística: el montaje voluntariamente ambiguo va en esta dirección. No importa que las asociaciones de los oyentes sean imposibles de conocer o medir, lo importante es hacer de la obra un intercambio vivo, como un ida y vuelta entre los sonidos y las experiencias que surgen. El híbrido que propone Ferrari busca funcionar entonces entre música y experiencias, entre la morfología del sonido y el contenido subjetivo derramado por los oyentes.

Podemos encontrar en este punto un primer sentido colectivo, en este revivir, reinterpretar, reorganizar las experiencias a través del sonido. Se trata de un trabajo con uno mismo, de nuestra relación con lo vivido y de la evolución en las formas que generamos para interpretarlo. En cómo, a partir de la proyección de lo vivido, las experiencias ganan en espesor de sentido.

12 Luc FERRARI « Hétérozygote - J'ai été coupé ", Edición Vinilo LP, Phillips, 1969. La traducción es nuestra. Original: "Un jour, je suis parti pour des raisons que je n'expliquerai pas, avec un magnétophone qui n'était pas à moi. J'ai voyagé, pas très loin, mais beaucoup et j'ai enregistré des choses de la vie. Ainsi est né "Hétérozygote", c'était la première pièce d'un genre que j'ai appelé musique anecdotique. [...] L'emploi d'éléments réalistes me permettait de raconter une histoire, ou permet à l'auditeur de s'inventer des images, car le montage propose des ambiguités [...]. Ce qui m'intéresserait, c'est qu'Hétérozygote me soit raconté par d'autres qui m'en écriraient l'histoire et qu'ainsi le disque ne soit pas un objet abstrait, mais qu'il soit un échange vivant." 


\section{EXPERIENCIA Y CRISTALIZACIÓN}

Ya sea en lo verdadero, lo medianamente verdadero o en lo falso: Luc Ferrari a menudo se convierte en el tema de las obras. De hecho, escuchando su música, acompañamos al compositor, o más bien a su representación construida por él mismo, en su vida personal. Este gesto implica un riesgo: el de caer en el narcisismo, la megalomanía o el exhibicionismo. En relación al tema, el compositor explica en una entrevista con David Sanson:

No entiendo bien la palabra egocentrismo [nombrilisme en el original]. Realmente me gustan las personas que hablan por sí mismas, es una forma de tomar una posición en la tierra, en las artes, en la creación. Lo que no me gusta es lo que es megalómano. La «música anecdótica» favorece en ese sentido una relación totalmente subjetiva. [...]. Casi nada es absolutamente objetivo: no se puede decir que los micrófonos son objetivos, no más que su ubicación, el momento en que grabamos $[. . .]^{13}$ (Sanson y Macé, 2004)

Hablar de él mismo es para Ferrari una forma de adoptar una posición en el mundo. El autor afirma la expresión de su subjetividad en varios niveles: en la composición musical, por supuesto, pero también en la colocación de los micrófonos, en la elección de los sonidos captados, en el gesto de compartir su sensibilidad respecto a los sonidos que lo rodean. Lejos de una presunción de objetividad, lo anecdótico enaltece la relación subjetiva del compositor con el mundo.

Explotar su subjetividad artísticamente, compartir su escucha del entorno dentro de la música, es un camino que Ferrari nunca detendrá a lo largo de su carrera como compositor. Hétérozygote marca el comienzo de dicho recorrido. En esta obra, su imagen personal todavía está casi ausente: aún no se trata de «Luc Ferrari». Si la pieza favorece una relación subjetiva en cuanto a las elecciones de sonidos y las situaciones de su vida personal que aparecen, su persona se borra deliberadamente. Todavía suponemos, de alguna manera, su figura detrás de la edición, la grabación de sonido y la composición. Es el mismo caso en

13 La traducción es nuestra. Original: "Je ne comprends pas bien le mot nombriliste. J'apprécie beaucoup les gens qui parlent d'eux-mêmes, c'est une façon de prendre position sur la terre, dans les arts, dans la création. Ce que je n'aime pas, c'est ce qui est mégalo. Les "musiques anecdotiques" privilégient ainsi un rapport totalement subjectif. Et c'est important, car ceux qui sont objectifs sont en fait subjectifs à un degré supérieur, c'est-à-dire le pire. Quand on se dit objectif, cela veut dire : j'ai raison. C'est idiot... Presque rien n'est absolument pas objectif : on ne peut pas dire que des micros soient objectifs, pas plus que leur emplacement, le moment auquel on enregistre [...] ". 
Presque rien $n^{\circ}$ I ou le lever du jour au bord de la mer, donde su figura es tácita dentro de la obra. Estas piezas de los años sesenta y principios de los setenta darán un primer impulso, que definitivamente aparecerá durante la década de I970. Incluso si el impulso es tímido en comparación con lo siguiente, la relación subjetiva que expresan estas piezas es el primer boceto de una búsqueda que se desarrollará sin detenerse a partir de entonces.

Podemos citar otro ejemplo con el drama musical en un acto Journal Intime, un musical para narrador, pianista y cantante. En esta obra, Ferrari trabaja desde la puesta en escena de su diario personal de la época. El compositor selecciona, retrabaja, recompone su diario, escrito entre i980 y I982, así como varias piezas para piano también compuestas en ese momento. Los diarios personales son textos que a priori no tienen otro destinatario que los que los escriben: se ubican en el territorio de lo íntimo. La obra coloca al oyente entonces en una posición de voyeur fortuito, en el ámbito emocional de la confidencia. Sin embargo, debe enfatizarse la arbitrariedad en la elección de dichos ejemplos: no son muchas las piezas de Luc Ferrari, especialmente aquellas para cinta magnetofónica, ajenas a la experiencia personal del compositor. Para Ferrari, su vida y sus obras están íntimamente vinculadas. ${ }^{14}$

Estas narraciones de experiencias personales involucran también un sentido colectivo. A la pregunta consecuente a dicha afirmación, sobre cómo puede el gesto de narrar experiencias, íntimas de a momentos, implicar dicha dimensión se intentará responder a partir de los pensamientos de escritores de distintas épocas, comenzando por Walter Benjamin.

Walter Benjamin analiza la importancia de los relatos en la construcción de nuestros vínculos sociales. Las historias son, para Benjamin, vehículo de las experiencias que, transmitidas a través de las generaciones, consolidan un pilar en la construcción de nuestra memoria colectiva. Como veremos parcialmente, la temática es abordada en muchos de sus textos. En «El narrador», publicado en I936, escribe lo siguiente: «El narrador extrae lo que cuenta de la experiencia, de su propia experiencia y la que le fue contada. Y vuelve a ser una experiencia para aquellos que escuchan sus historias» (Benjamin, 20II: 62). En otro extracto del mismo texto podemos leer:

14 Otros ejemplos, para complementar la descripción: Les Arythmiques (2003), luego del diagnóstico de un problema cardíaco. Far West News, que cuenta el viaje por Estados Unidos de la pareja Ferrari. Cycle des souvenirs (1998-99), entre otros. 
De hecho, podemos ir más allá y preguntarnos si la relación que el narrador tiene con su vida material y humana no es en sí misma una relación artesanal. ¿La tarea del narrador no consiste en dar forma a la materia prima de la experiencia, extranjera y personal, de una manera sólida, útil y única? ${ }^{15}$ (Benjamin, 20II: IO5)

Para Benjamin, el narrador trata las historias (ajenas y personales) artesanalmente ${ }^{16}$, de una «forma sólida, útil y única». La idea es entonces vehiculizar un mensaje, un aprendizaje, a través de las generaciones. Esta experiencia, moldeada a través del tiempo, se transmite y se reconfigura, se revive a través de sus narrativas sucesivas. Para este tipo de experiencia, Benjamin utiliza el término Erfahrung. Retomando la definición de experiencia de comienzos del escrito y los dos aspectos que el término recubre, Erfahrung corresponde a experiencia como cristalización de lo vivido. El filósofo reflexiona entonces acerca del concepto en cuanto a su transmisión a través de las historias y su importancia para el devenir colectivo.

La teorización de dicha visión de la experiencia se da en el pensamiento de Benjamin en un marco crítico respecto a la sociedad de la época (años previos y principios de la segunda guerra mundial). En «Experiencia y pobreza» y «Sobre algunos temas en Baudelaire», por ejemplo, hablará sobre la pérdida de Erfahrung en pos de otro tipo de experiencia, Erlebnis, apuntalada por el «nuevo mundo». Erlebnis, en la visión de Benjamin, es asociada a la experiencia de la publicidad, de la propaganda política, de la instantaneidad de las noticias. En contraste con su visión de Erfahrung, Erlebnis es una experiencia individual, sin contexto, inútil para el vivir común. Los musicólogos Makis Solomos y Frédérick Duhautpas explican estas ideas para analizar una obra de la compositora canadiense Hildegard Westerkamp. Escriben:

El modo de experiencia específica en el nuevo mundo está determinado por el crecimiento de la tecnología (incluidas características como la velocidad y el flujo de información), que establece Erlebnis, un tipo de experiencia inscripta en la reacción primaria, en el momento presente y efímero, en detrimento de

15 La traducción es nuestra. Original: On peut en effet poursuivre plus loin et se demander si la relation que le conteur entretient avec sa matière, la vie humaine, n'est pas elle-même une relation artisanale. La tâche du conteur ne consiste-t-elle pas justement à façonner la matière brute de l'expérience - étrangère et personnelle - d'une manière solide, utile et unique?

16 En un texto sobre Baudelaire, llega a decir que el narrador deja la marca de sus experiencias en las historias, como el alfarero que deja la marca de sus manos en el jarrón que moldea. Ver: Benjamin, 1974, p.154. 
Erfahrung, quien introduce la posibilidad de una memoria colectiva y continua. ${ }^{17}$ (Duhautpas y Solomos, 20I4)

Por lo tanto, en la visión de Benjamin, existen transmisiones de experiencias que ponen en juego cuestiones diferentes, diferenciando en este punto entre Erfahrung y Erlebnis. Llegamos aquí a una segunda idea respecto a la música de Luc Ferrari: asociar la forma de narrar del compositor a lo que Benjamin define como Erfahrung (y que Jean-Marie Schaeffer, retomando la definición del comienzo, asocia a la cristalización de lo vivido). La «anécdota» a la que el autor se refiere encaja en esta línea, se trata de un «tratamiento artesanal» de su experiencia personal, contada en obras musicales, que buscan hacer resonar lo vivido en los oyentes. Como vimos anteriormente, Ferrari considera esta dimensión. No se trata entonces solamente de una búsqueda morfológica abstracta, fuera de todo contexto, se trata de buscar reforzar lo común en las experiencias colectivas.

\section{LO COLECTIVO EN EL GESTO DE CONTARSE}

La escucha de Chantal, ou le portrait d'une villageoise puede resultar útil para ejemplificar ideas que se busca proponer. Chantal... es una obra de 1976 que presenta diálogos entre el compositor, Brunhild Ferrari ${ }^{18}$ y una joven que vive en un pueblo de 800 habitantes ${ }^{19}$; y grabaciones de guitarras. Las guitarras construyen la forma musical de la obra, articulando por momentos las distintas conversaciones y consolidando hacia el medio de la pieza un momento de tensión y deconstrucción sonora general. Por su lado, la joven cuenta, a través de las preguntas de la pareja Ferrari, sobre su vida en el pueblo, sus sensaciones, su vida cotidiana. Escuchamos a Chantal contarnos, con sus 22 años, su maternidad siendo muy joven, las dificultades experimentadas al enfrentar la situación, cómo siente su vida en diferentes facetas: como mujer, como madre

17 La traducción es nuestra. Original: "The mode of experience specific to the new world is determined by the growth of technology (including characteristics such as speed and circulation of information), which establishes Erlebnis, a type of experience inscribed in primary reaction to the present and ephemeral moment, at the expense of Erfahrung, which introduces the possibility of a collective and continuous memory."

18 El uso del apellido Ferrari, en lugar de Meyer, corresponde a una elección de la compositora.

19 Hablamos de Tuchan, el pueblo donde se grabó la obra. Fuente del número de habitantes: Institut national de statistiques et des études économiques (INSEE). Número de habitantes de Tuchan en 1975. https://www.insee.fr/fr/ statistiques/2011101?geo=COM-11401 Consultado el 30 de abril de 2020. 
joven, como pueblerina a mediados de los '70 en el contexto rural francés. La obra es en gran parte el ejercicio de alguien que intenta comprenderse retrospectivamente, que intenta analizar lo que ocurrió.

Contarse, transformar la experiencia en historia, juega un papel en nuestra construcción social. Como explica Roselyne Orofiamma, a partir de una cita de Josselson:

Las verdades inherentes a cualquier historia personal surgen de un verdadero arraigo en el mundo, en lo que hace a la vida: pasiones, deseos, ideas, sistemas conceptuales. Las historias personales de los individuos son esfuerzos para comprender la confusión y la complejidad de la condición humana. ${ }^{20}$ (Orofiamma, 2002)

Hay una verdad inherente en el acto de contarse a sí mismo, en el impulso de convertir la experiencia en una historia para los demás. Hablamos de una verdad que existe por su anclaje en el mundo: por el esfuerzo de comprender una realidad vivida, destacando una complejidad que es común en las personas. La historia de vida es un despliegue de personas en construcción: con un narrador-explorador, que explora y estructura su sensibilidad, y oyentes, que distinguen empáticamente sus propias sensaciones en la historia y las exploran en el mismo movimiento.

Como explica Orofiamma, en la auto-narrativa hay una duplicación del sujeto: entre el que cuenta y el que es contado: "Como situación de enunciación y cualquiera sea la forma que tome la auto-narrativa, pone en juego un sujeto que habla y un sujeto biográfico: el yo que cuenta y el yo contado.» ${ }^{21}$ En el momento en que Chantal cuenta su embarazo, por ejemplo, tenemos a "Chantal que cuenta» y a "Chantal embarazada». En consecuencia, Chantal hace un esfuerzo para salvar esa distancia, a través de la actualización de sus experiencias pasadas. Es precisamente en este movimiento hacia el pasado donde radica la dimensión humana en la historia, en la iniciativa de comprender qué sucedió. Este desplazamiento de experiencias hacia el presente en forma de narra-

20 Ruthellen Josselson citado por Orofiamma, 2002. La traducción es nuestra. Original: "Les vérités inhérentes à tout récit personnel naissent d'un véritable ancrage dans le monde, dans ce qui fait la vie - les passions, les désirs, les idées, les systèmes conceptuels. Les récits personnels des individus sont autant d'efforts pour saisir la confusion et la complexité de la condition humaine. "

21 Claude Abastado citado por Orofiamma, 2008. La traducción es nuestra. Original: "En tant que situation d'énonciation et quelle que soit la forme que prend le récit de soi, il met en jeu un sujet locuteur et un sujet biographique : le je qui raconte et le moi raconté." 
ción es, sobre todo, una exploración, una reconfiguración, compromisos de un narrador que se expresa a sí mismo:

A través del relato, el proceso de formación implica cuestionar el desarrollo de un recorrido, los caminos tomados para constituir lo que gradualmente se convierte en una historia personal, de la cual el sujeto que busca ser narrado es también el narrador. El relato acompańa este esfuerzo para dar forma a la experiencia vivida, para comprender cómo está hecha de pasiones, deseos, valores, creencias, en cómo las verdades que emergen de ella se fundan sobre las singularidades irreducibles de cada uno [...]. Pero si el trabajo de la narración tiene como objetivo comprender una experiencia singular, es quizás y sobre todo un esfuerzo por comprender, a través de ella, lo que se experimenta de la condición humana en su complejidad, su confusión y su carácter incompleto. $^{22}$ (Orofiamma, 2002)

En este sentido, hablamos de esfuerzo, porque la conformación de nuestras experiencias en forma de historia es un intento por dar orden a lo que no lo tiene. El narrador está lidiando con una mezcla de imágenes, emociones, sensaciones: un complejo sensible del cual debe extraer un ordenamiento, una forma. "La narración se presenta como un sistema organizado que requiere encontrar cohesión donde solo hay un conjunto incierto de eventos dispersos $[\ldots]{ }^{23}$. La misma persona tiene infinitas posibilidades para contar la misma historia. Cuenta una historia entre todas las posibles, comprometiendo así cada vez su subjetividad y su relación con el mundo. Lo importante, entonces, no es saber si la historia corresponde o no a lo que sucedió en el nivel de los hechos, «sino más bien reconocer que en este trabajo de narración, el sujeto está en construcción»(Orofiamma, 2002).

Ahora bien, si todo relato personal tiende a implicar lo colectivo, no todos los relatos aluden a cuestiones similares. Nuestra experiencia cotidiana actual

22 La traducción es nuestra. Original: « Par le récit, le processus de formation engage à questionner le déroulement d'un parcours, les voies empruntées pour constituer ce qui devient progressivement une histoire personnelle dont le sujet qui cherche à en rendre compte est aussi le narrateur. Le récit accompagne cet effort pour mettre en forme le vécu de l'expérience, pour comprendre en quoi celle-ci est faite de passions, de désirs, de valeurs, de croyances, en quoi les vérités qui s'en dégagent se fondent sur les singularités irréductibles à chacun, mais aussi sur ce qui fait leur ancrage dans un monde social, dans des univers culturels et institutionnels, dans des appartenances familiales dont les projets et les aspirations marquent toujours les destins individuels. Mais si le travail du récit vise la compréhension d'un vécu singulier, il est peut-être et surtout un effort pour saisir, à travers lui, ce qui s'éprouve de la condition humaine dans sa complexité, sa confusion et son inachèvement."

23 Ibid.

REVISTA DEL ISM I7 | 2020 | 55 
nos muestra historias personales en permanencia y no todas ellas tienen el mismo alcance político. Al respecto, Leonor Arfuch propone ideas pertinentes. Tomando en cuenta la presencia que conforman todas las declinaciones de las «intimidades públicas» actuales (léase reality shows, docudramas, autobiografías literarias, propaganda política, redes sociales, entre otros), la autora conceptualiza la idea de espacio biográfico «para dar cuenta de esa convivencia aparentemente sin conflictos de expresiones multifacéticas, no comparables a escala valorativa, pero que sin embargo tenían rasgos en común» (Arfuch: 20I8, p. 19). Inicialmente a partir del estudio de la biografía y la autobiografía, Arfuch monta un dispositivo conceptual para tratar de buscar continuidades en la masa de imágenes y emociones personales que nos inundan a través de diferentes medios. Arfuch, como Benjamin casi un siglo antes, reflexiona en términos éticos sobre el fenómeno. La autora escribe en «Arte, memoria, experiencia: políticas de lo real»:

Así, más allá de la obvia referencia narcisistica -muy marcada en algunas trayectorias- toda exposición personal tiende a involucrar lo colectivo, ya sea de modo explícito, en relación a las políticas de identidad y los nuevos movimientos sociales -dos registros preponderantes en nuestros días-, como, intrínsecamente, por la alusión a pautas y valores compartidos. El viejo adagio feminista de «lo personal es político» encuentra sin duda en el arte uno de sus mejores terrenos de manifestación. (Arfuch, 2004)

Arfuch explica cómo, más allá del riesgo narcisista, hay una tendencia a lo político en las exposiciones personales; pudiendo ser de modo explícito, es decir nombrando abiertamente dicha dimensión, o bien implícito, por alusión a pautas y valores compartidos. Las elecciones, posicionamientos, formas de hacer frente y reaccionar del sujeto narrado proyectan mensajes indirectamente, son posicionamientos que se prestan a ser pensados. Volviendo a Ferrari, ¿¿Dónde encontramos, en el caso de Chantal, alusiones a pautas o valores compartidos que pueden involucrar lo colectivo de modo intrínseco? Los encontramos en darle la palabra a una mujer joven para que cuente su vida en los años '70 en medio del mundo rural. En proponer una obra como un espacio para la escucha, no sólo para los auditores sino también en el gesto de posicionar la figura del compositor escuchando ${ }^{24}$. En abordar junto a Chantal ideas difíciles de ser escuchadas, tanto en la época de la obra como quizá también en la actual: su

24 En la obra, escuchamos escuchar a Ferrari. 
eventual arrepentimiento de haber sido madre, su relación con el aborto, su visión crítica respecto a la monogamia.

La obra reivindica indirectamente la potencialidad política de la escucha. Con la composición a partir de la voz de Chantal pensándose, Ferrari despliega un gesto que posee una vocación ética, una búsqueda de pensar los lazos: los de Chantal con ella misma, y los nuestros en resonancia. Chantal intenta comprenderse, trabaja la construcción de su subjetividad a través de la narración de sus experiencias, y nosotros auditores, lo hacemos también, en resonancia.

\section{Conclusiones}

Para ir concluyendo, se propone repasar cuestiones que consideramos relevantes dentro de lo nombrado. Primero, como escribe Norman, remarcar que las músicas que utilizan field recording (realworld sounds, en sus palabras) pueden poner en juego cuestiones que tienen que ver con la experiencia: la del compositor, quien las vive personalmente y las graba, y la de los auditores, quienes proyectan las suyas. Esta resonancia de lo vivido, esta vuelta al presente del pasado a partir de las obras, tiene, en sí, un sentido colectivo. Las experiencias son reinterpretadas, ganamos en nuestra comprensión de nosotros mismos.

Segundo, remarcar que el término experiencia puede ser equívoco, ya que hace referencia tanto a cuestiones interaccionales (sensitivas, principalmente) como también a la acumulación y utilidad retrospectiva de dichas interacciones. La distinción es pertinente, ya que si pensamos en términos éticos la experiencia que pone en juego este tipo de obras, debemos pensar si se trata de cuestiones sensitivas (que se quedan en la superficie) o bien si se trabajan cuestiones relativas a la cristalización de lo vivido, relativas a la memoria y su continuidad entre lo individual y lo social. El pensamiento de Benjamin sobre los narradores y la construcción de Erfahrung nos fue de utilidad en ese sentido.

Finalmente, podemos decir que la música de Ferrari busca trabajar las experiencias siguiendo este último camino. Narrando sobre sí mismo pero sin caer en la megalomanía, mostrando su vida con el acento en lo común que nos une: en lo que nos es próximo, cotidiano. También, siguiendo el pensamiento de Arfuch, Ferrari alude a valores que tienen sentido para nuestra interacción como sociedad, dándole la palabra a voces que pudieron ser silenciadas, creando espacios para que todos pensemos, directa o indirectamente, cómo interpretamos lo ocurrido. 


\section{Fuentes}

Ferrari, L. (1969). Hétérozygote - J'ai été coupé, Edición Vinilo LP, Phillips

\section{Bibliografía}

Arfuch, L. (2004). Arte, memoria, experiencia: políticas de lo real. Confines, $\mathrm{N}^{\circ} 15$, pp. $111-120$

(2018). La vida narrada: memoria, subjetividad y política, Villa María, Argentina, Eduvim

Benjamin, W. (1974). Charles Baudelaire: un poète lyrique à l'apogée du capitalisme. Paris: Éditions Payot

(2000). Oeuvres. Tome III. Paris: Gallimard

(2011). Expérience et pauvreté - suivi par Le conteur et La tâche du traducteur. Paris: Éditions Payot \& Rivages

Benson, S. y Montgomery, W. (2018). Writing the Field Recording: Sound, Word, Environment. Edinburgh: Edinburgh University Press

CARR, D. (2014). Experience and history: phenomenological perspectives on the historical world, New York: Oxford University Press

Caux, J. y Ferrari, L. (2002). Presque rien avec Luc Ferrari: entretiens. Nice: Main d'œuvre

Cobussen, M., Meelberg, V., y Truax, B. (Eds.). (2016). The Routledge companion to sounding art. New York: Routledge

Chion, M. (1999). El sonido. Música, cine, literatura... Barcelona: Paidós (2009). La musique concrète, art des sons fixés. Lyon: Editions Mômeludies

Duhautpas, F. y Solomos, M. (2014). Hildegard Westerkamp and the Ecology of Sound as Experience. Notes on Beneath the Forest Floor. Soundscape, The Journal of Acoustic Ecology, vol. 13, no. 1

Herrero, L. (2019). Conferencia en "Músicos en Congreso - VII edición» Santa $\mathrm{Fe}$, Argentina. Sin edición

Macḱ, P-Y. (2009). Phonographies documentaires : étude du document sonore dans la musique depuis les débuts de la phonographie, Tesis doctoral, Université de Paris 8

MÂche, F-B. (1998). Entre l'observatoire et l'atelier. Paris: Éditions Kimé

Norman, K. (1994). Telling tales. Contemporary Music Review, vol. 10, $\mathrm{n}^{0} 2$, pp. $103-109$

(1996). Real-World Music as Composed Listening. Contemporary Music Review, vol. 15, pp. 1 - 27 
(2010). Conkers (Listening out for Organised Experience), Organised Sound, vol. $15, n^{\circ} 2$, pp. 116-124

Orofiamma, R. (2002). Le travail de la narration dans le récit de vie.

Niewiadomski \& de Villers (Éds.). Souci et soin de soi, Liens et frontières entre histoire de vie, Psychothérapie et psychanalyse, pp. 163-191. Paris: Éditions L'Harmattan

(2008). Les figures du sujet dans le récit de vie. Informations sociales, $\mathrm{n}^{\circ} 145$, no. 1 , pp. $68-81$

Reyna, A. (2016). La construction de l'hétérogène en la musique de Luc Ferrari : lieu, récit et expériences. Analyses de Hétérozygote, Far West News et Chantal, ou le portrait d'une villageoise. Tesis doctoral, Universidad de Paris 8

SANSON, D. \& MACÉ, P-Y. (2004). Le hasard avec détermination - Rencontre avec Luc Ferrari. Recuperado de http://www.mouvement.net/teteatete/entretiens/lehasard-avec-determination [consultado el 8 septembre 2015]

Smalley, D. (1994). Defining Timbre, Refining Timbre. Contemporary Music Review Vol. 10, no. 2.

Solomos, M. (2018). L'écoute musicale comme construction du commun. Circuit: musiques contemporaines, vol. 28, no. 3, p. 53 - 64

Schaeffer, J-M. (2015). L'expérience esthétique. Paris: Gallimard

Schaeffer, P. (1952). À la recherche d'une musique concrète. Paris: Éditions du Seuil

(1966). Traité des objets musicaux: essai interdisciplines. Paris: Éditions du Seuil

\section{Registro bibliográfico}

Alejandro Reyna: «La experiencia narrada como vehículo de construcción colectiva en la música de Luc Ferrari», en Revista del Instituto Superior de Música, número 17, Instituto Superior de Música, Santa Fe, UNL, República Argentina, 2020, pp. 43-59.

Descriptores / Describers

Luc Ferrari - Experiencia · Field recording 